ORIGINAL PROF-2081

\title{
ORAL HEALTH OF PREGNANT WOMEN;
}

Knowledge, attitude and practice at antenatal care clinic in Morogoro Municipal, Tanzania

\section{Dr. Byanaku A K, Dr. Rwakatema D S.}

ABSTRACT...... Objective: To assess level of knowledge, attitude and practice on oral health mong pregnant women attending antenatal care clinic in Morogoro Municipal, Tanzania. Design: A cross sectional study. Setting: Morogoro Municipality, Morogoro Region, Tanzania. Subjects and Methods: Pre tested questionnaires were administered randomly to 216 participants attending antenatal care clinic seeking to find out quantitative data on their specific socio-demographic characteristics, oral health knowledge, attitude and practice in 2012. A sample of 26 participants was involved in focus group discussions (FGD's). Questionnaire data were analyzed by Stata Version 12.1 programme. Chi-square test and Logistic regression models were used. A p-value $<0.05$ was considered significant. FGD's qualitative data analysis was done manually using thematic framework analysis. Results: Majority (73\%) of the participants had adequate oral health knowledge. About $76 \%$ of the respondents agreed to the positive statements towards oral health. Focus Group Discussions revealed negative attitude towards dental treatment during pregnancy. Adequate oral health practice was found in majority of the participants (72\%). Levels of education and marital status of the participants were found to be strongly associated with oral health practice ( $p$-value $<0.05$ ). Conclusions: Majority of the participants had overall adequate knowledge, practice and positive attitude towards oral health. However, unsatisfactory knowledge on possible connections between bleeding gums and pregnancy and negative attitude towards dental visits were noted. Level of education was significantly associated with oral health practice and attitude. Dental visits from the first stages of pregnancy should be part of antenatal care clinic in this community.

Key words: Oral health, knowledge, attitude, practice, oral health in pregnancy

Article Citation

Byanaku AK, Rwakatema DS. Oral health of pregnant women; Knowledge, attitude and practice at antenatal care clinic in Morogoro Municipal, Tanzania. Professional Med J 2013;20(3): 365-373.

\section{INTRODUCTION}

Oral health is a key component of overall health and well being of a woman across the life span. It is an important consideration prior to conception and during pregnancy ${ }^{1}$. The physical changes during pregnancy may increase woman's susceptibility to oral conditions. These are mainly gingivitis and periodontitis which have been reported to range between $36-100 \%{ }^{2}$. There is a report of suspicion on association between periodontal diseases and adverse pregnancy outcomes such as premature birth, low birth weight and pre-eclampsia ${ }^{3}$.

Study reports worldwide have shown at least inadequacy or gaps on the knowledge, attitude or practice of oral health in pregnant women ${ }^{4-8}$. The change to oral health attitude and practice can be attained by given adequate oral health information and motivation $^{9}$. In order to create such health education, the assessment of knowledge, attitude and practice is essential in a given community ${ }^{10}$.

Several programs on the provision of oral health knowledge, attitude and promoting good oral health practice in Morogoro, Tanzania have been primarily focused on children and other populations. None documentation has been done to pregnant women despite being the risky group for oral diseases. This study aimed to find the magnitude of knowledge, attitude and practice of oral health in pregnant women attending antenatal care clinic in Morogoro Municipality, Tanzania. The findings will contribute greatly to the baseline information necessary for planning comprehensive oral health care in pregnant women in this community hence the society at large.

\section{MATERIALS AND METHODS}

This was a cross sectional study conducted in urban areas of Morogoro Municipality among the pregnant women attending antenatal clinic in 2012. The study 
evaluated their oral health knowledge, attitudes and practices. Ethical clearance was sought from Kilimanjaro Christian Medical Centre Ethical Committee in Tanzania. A written informed consent was obtained from each of the pregnant women who participated. There were 36 health facilities running antenatal clinic in Morogoro, Tanzania. Stratification and simple random method were used to select 8 health dispensaries, 4 health centres and 2 hospitals in which the sample for quantitative data was randomly drawn. A total of 216 pregnant women were selected and agreed to participate for quantitative data collection. Based on a previous report on the prevalence of oral health knowledge among pregnant women in Tanzania ${ }^{11}$ this number constituted a representative sample. Focus group discussions' (FGDs') sample for qualitative data comprised of 26 participants selected from three health facilities which were randomly selected. These three Health facilities were not involved in the quantitative data collection. Three FGDs' were generated in which the participants were purposively selected based on age groups used in the quantitative study. Similar age group comprised one FGD. This intended to allow participant's to feel free to express their ideas without feeling uneasy of a young or elderly fellow participant.

Data were collected in two parts, first, by interview of the participants using a pre-tested open and close ended questionnaire. Secondly a Focus Group Discussions (FGD's) were conducted in Kiswahili the language which is well known in Tanzania by the participants. The aim of the focus group discussion was to compliment and validate quantitative data in the aspects of oral health attitude. A total of 7 questions probing on knowledge, 5 on attitude and 7 on practice to oral health respectively were involved. All questions were given equal weight of 1 point for correct response and 0 point for incorrect response. The cut-off points for an individual level of oral health knowledge, attitude and practice were set at4,3 and 4 points respectively. Those who scored at the cut-off point and above were graded as having adequate knowledge, positive attitude and adequate oral health practice respectively. The opposite was true for those who scored below the cut-off point.

Data collected by using questionnaires were coded into numerical and fed to the computer for analysis using statistical package (Stata Version 12.1). Chisquare test was used to evaluate for any significant differences between specific social demographic factors of the participants on their levels of knowledge, attitude and practice. A p-value of 0.05 was considered significant. Univariate and Multivariate regression analysis was done to assess the effect and strength of independent (predictor) variables on the outcomes of interest and also for control/adjusting of confounders. In the logistic regression models the association between predictors and outcomes was measured by odds ratio at 95\% confidence intervals. FGD's data analysis on oral health attitude was done by using thematic framework analysis which involved five main stages. These were familiarization, identifying thematic framework, indexing/coding, charting, mapping and interpretation.

\section{RESULTS}

Out of 216 pregnant women sampled out the response rate was $100 \%$ in the entire domains studied. Table I shows the distribution of socio-demographic characteristics of the respondents. The age of the respondents ranged between 16 and 45 years (mean $=25.8, \mathrm{SD} \pm 5.4)$. Half of the participants 108 (50\%) were in the young age group ranging between 16-25 years. More than half of the participants were married 129 (59.72\%). More than half 128 (59.3\%) had primary education while $19(8.8 \%)$ had never gone to school. Large proportion of the women interviewed $134(62.1 \%)$ were in their second parity.

Table-Il summarises the oral health knowledge domain responses. In this domain more than half 129 (59.7\%) of the respondents had correct responses on the 


\begin{tabular}{|l|c|c|}
\hline & \multicolumn{2}{|c|}{ Respondents } \\
\hline \multicolumn{1}{|c|}{ Demographic characteristics } & $\mathbf{n}$ & (\%) \\
\hline Age (years) & 108 & 50 \\
$16-25$ & 99 & 45.8 \\
$26-35$ & 9 & 4.2 \\
$36-45$ & & \\
\hline Marital status & 129 & 59.72 \\
Married & 87 & 40.28 \\
Not Married & & \\
\hline Level of education & 19 & 8.8 \\
Never gone to school & 128 & 59.3 \\
Primary education & 69 & 31.9 \\
Higher education & \multicolumn{2}{|c|}{} \\
\hline Parity & 82 & 37.9 \\
First parity & 134 & 62.1 \\
Second and above & Table-l. Specific demographic characteristics of the pregnant \\
\multicolumn{2}{|c|}{ women in Morogoro, Tanzania (N=216) } \\
\hline
\end{tabular}

question of whether brushing teeth with fluoridated toothpaste could prevent dental caries. Majority 186 $(86.1 \%)$ of the respondents had correct responses on the frequency of sugary foods consumption in relation to tooth decay. Moreover 168 (77.8\%) knew that presence of a cavity in a tooth indicates dental caries. Almost two thirds 145 (62.5\%) of the participants had incorrect responses on bleeding gums in relation to gum diseases. Out of the 216 respondents, 159 $(73.6 \%)$ had an adequate knowledge of oral health (scored $\geq 4$ points). The mean score was 4 points $(\mathrm{SD} \pm 1.4)$.

Oral health attitude domain responses of the participants are summarised in Table III. Most of the participants $165(76.4 \%)$ agreed that oral health is important for them and their baby. Less than half 64 $(29.6 \%)$ responded positively to the negative statement that dental treatment is harmful during pregnancy. Among the respondents 92(42.6\%) responded positively to the negative statement that they are supposed to visit a dentist only when having dental problems. Majority of the participants 197 $(91.2 \%)$ had positive response on the necessity of cleaning teeth every day. Overall 137(63.4\%) had positive attitude on oral health (scored $\geq 3$ points). The mean score was 3 (SD \pm 1.2$)$.

Table-IV present oral health practice domain responses of the participants. Correct response on the frequency of tooth brushing was seen in 141(65.3\%) respondents who brushed their teeth either twice or more than twice per day. Almost all participants $212(98.2 \%)$ responded correctly on the correct

\begin{tabular}{|c|c|c|c|c|}
\hline \multirow[b]{3}{*}{ Item probed } & \multicolumn{4}{|c|}{ Oral health knowledge responses } \\
\hline & \multicolumn{2}{|c|}{ Correct } & \multicolumn{2}{|c|}{ Incorrect } \\
\hline & n & $\%$ & n & $\%$ \\
\hline Brushing teeth with fluoridated tooth paste & 129 & 59.7 & 87 & 40.3 \\
\hline Consumption of sugary foods causes tooth decay & 186 & 86.1 & 30 & 13.9 \\
\hline Presence of cavity indicates tooth decay & 168 & 77.8 & 48 & 22.2 \\
\hline Brushing teeth alone prevent gum disease & 143 & 66.2 & 73 & 33.8 \\
\hline Bleeding during tooth brushing indicates gum disease & 81 & 37.5 & 145 & 62.5 \\
\hline Timely detect of oral diseases & 138 & 63.9 & 78 & 36.1 \\
\hline Poor oral health affect unborn baby & 120 & 55.5 & 96 & 44.5 \\
\hline Overall oral health knowledge & 159 & 73.6 & 57 & 26.4 \\
\hline
\end{tabular}

Table-II. Distribution of pregnant women responses on specific items of oral health knowledge in Morogoro, Tanzania (N=216) 


\begin{tabular}{|c|c|c|c|c|}
\hline \multirow[b]{3}{*}{ Statement probed } & \multicolumn{4}{|c|}{ Responses } \\
\hline & \multicolumn{2}{|c|}{ Positive } & \multicolumn{2}{|c|}{ Negative } \\
\hline & $\mathbf{n}$ & $\%$ & $\mathbf{n}$ & $\%$ \\
\hline $\begin{array}{l}\text { Oral health important to you and } \\
\text { unborn baby }\end{array}$ & 165 & 76.4 & 51 & 23.6 \\
\hline $\begin{array}{l}\text { Tooth brushing is not important for } \\
\text { dental carries }\end{array}$ & 118 & 56.4 & 98 & 45.4 \\
\hline $\begin{array}{l}\text { Dental treatment harmful during } \\
\text { pregnancy }\end{array}$ & 64 & 29.6 & 152 & 70.4 \\
\hline $\begin{array}{l}\text { Going to dentist only when having } \\
\text { tooth pain }\end{array}$ & 92 & 42.6 & 124 & 57.4 \\
\hline $\begin{array}{l}\text { Not necessary to clean teeth } \\
\text { everyday }\end{array}$ & 197 & 91.2 & 19 & 9.8 \\
\hline Overall attitude of the respondents & 137 & 63.4 & 57 & 26.4 \\
\hline
\end{tabular}

\begin{tabular}{|c|c|c|c|c|}
\hline \multirow[b]{3}{*}{ Items probed } & \multicolumn{4}{|c|}{ Responses } \\
\hline & \multicolumn{2}{|c|}{ Correct } & \multicolumn{2}{|c|}{ Incorrect } \\
\hline & $\mathbf{n}$ & $\%$ & $\mathbf{n}$ & $\%$ \\
\hline How many times brushing teeth & 141 & 65.3 & 75 & 34.7 \\
\hline What time brush your teeth & 140 & 65.8 & 76 & 35.2 \\
\hline Type of dentifrices used & 212 & 98.2 & 4 & 1.8 \\
\hline Item used in brushing teeth pain & 143 & 66.2 & 73 & 33.8 \\
\hline $\begin{array}{l}\text { Visiting dentist before becoming } \\
\text { pregnant }\end{array}$ & 53 & 24.5 & 173 & 75.5 \\
\hline Ever gone dentist when pregnant & 44 & 20.4 & 172 & 79.6 \\
\hline Reason for previous dental visit & 43 & 19.9 & 173 & 80.1 \\
\hline Overall practice of the respondents & 156 & 72.7 & 57 & 27.7 \\
\hline
\end{tabular}

Table-IV. Distribution of pregnant women responses on specified items on oral health practice in Morogoro, Tanzania $(\mathrm{N}=216)$

substance used for brushing their teeth. Majority $173(75.5 \%)$ of the respondents never had the habit of visiting a dentist for dental check-up before or during pregnancy. Out of 216 respondents, 156 (72.2\%) had overall adequate practice of oral health (scored $\geq 4$ points). Mean score was 4 (SD \pm 1.3$)$.

The level of knowledge on oral health was independent of all the demographic factors analysed (Table-V). Table-VI and VII summarises the distribution of specific social demographic factors of the participants by their oral health attitude and practice levels respectively in

\begin{tabular}{|c|c|c|c|c|}
\hline \multicolumn{2}{|c|}{ Demographic factors } & \multicolumn{3}{|c|}{ Oral health knowledge } \\
\hline Age group & Not adequate & Adequate & Total & P-value \\
\hline $16-25$ & $34(31.5)$ & $74(68.5)$ & 108 & \\
\hline $26-35$ & $21(21.2)$ & 78(78.8) & 99 & 0.24 \\
\hline $36-45$ & $2(22.2)$ & $7(77.7)$ & 9 & \\
\hline \multicolumn{5}{|l|}{ Parity } \\
\hline First parity & $27(32.9)$ & $55(67.1)$ & 82 & \multirow{2}{*}{0.09} \\
\hline Second and above & $30(22.4)$ & 104(77.6) & 134 & \\
\hline \multicolumn{5}{|l|}{ Education level } \\
\hline Never gone to school & $7(36.8)$ & 12(63.2) & 19 & \multirow{3}{*}{0.27} \\
\hline Primary education & $36(28.1)$ & $92(71.9)$ & 128 & \\
\hline Higher education & $14(20.3)$ & $55(79.7)$ & 69 & \\
\hline \multirow{3}{*}{$\begin{array}{l}\text { Marital status } \\
\text { Married } \\
\text { Not married }\end{array}$} & & & & \multirow{3}{*}{0.74} \\
\hline & $33(25.6)$ & $96(74.4)$ & 129 & \\
\hline & $24(27.6)$ & $63(72.4)$ & 87 & \\
\hline \multicolumn{5}{|c|}{$\begin{array}{l}\text { Table-V. Distribution of specific social demographic factors of } \\
\text { the pregnant women by their oral health knowledge levels in } \\
\quad \text { Morogoro, Tanzania. } \\
\quad P>0.05 \text { (no significant difference); statistics: Chi-square test. }\end{array}$} \\
\hline
\end{tabular}

Morogoro, Tanzania. They also depict the association between the level of attitude and practice of oral health of the respondents with their socio-demographic characteristics respectively. The level of education was significantly associated with oral health attitude $(P<0.05)$. Those with primary education and higher had positive attitude compared to those who never went to school (Table-VI). Level of education was significantly associated with oral health practice $(\mathrm{P}<0.05)$ (Table-VII). Those with primary education and above had adequate practice compared to those who never went to school. Level of marital status was also significantly associated with oral health practice $(\mathrm{P}<0.05)$. Those who were married had more adequate practice compared to those who were not married (Table-VII).

Univariate and multivariate model analysis of association between respondent's levels of oral health knowledge, attitude and practice revealed knowledge to remain independent of socio-demographic factors 


\begin{tabular}{|c|c|c|c|c|}
\hline \multicolumn{2}{|c|}{ Demographic factors } & \multicolumn{3}{|c|}{ Oral health attitude level } \\
\hline Age group & Negative & Positive & Total & P-value \\
\hline $16-25$ & $37(34.3)$ & $71(65.7)$ & 108 & \\
\hline $26-35$ & $39(39.4)$ & $60(60.6)$ & 99 & $\nabla 0.73$ \\
\hline $36-45$ & $3(33.3)$ & $6(66.7)$ & 9 & \\
\hline \multicolumn{5}{|l|}{ Parity } \\
\hline First parity & $22(26.8)$ & $60(73.2)$ & 82 & $\Delta 0.02$ \\
\hline Second and above & $57(42.5)$ & $77(57.5)$ & 134 & \\
\hline \multicolumn{5}{|l|}{ Education level } \\
\hline Never gone to school & $14(73.7)$ & $5(26.3)$ & 19 & 0.001 \\
\hline Primary education & $58(45.3)$ & $70(54.7)$ & 128 & \\
\hline Higher education & $7(10.1)$ & $62(89.9)$ & 69 & \\
\hline \multicolumn{5}{|l|}{ Marital status } \\
\hline Married & $49(37.0)$ & $80(62.0)$ & 129 & $\Delta 0.60$ \\
\hline Not married & $30(34.5)$ & $57(72.4)$ & 87 & \\
\hline
\end{tabular}

\begin{tabular}{|c|c|c|c|c|}
\hline \multicolumn{2}{|c|}{ Demographic factors } & \multicolumn{3}{|c|}{ Oral health practice level } \\
\hline $\begin{array}{l}\text { Age group } \\
16-25 \\
26-35 \\
36-45\end{array}$ & $\begin{array}{c}\text { Inadequate } \\
33(30.6) \\
26(26.3) \\
1(11.1)\end{array}$ & $\begin{array}{c}\text { Adequate } \\
75(69.4) \\
73(73.6) \\
8(88.9)\end{array}$ & $\begin{array}{c}\text { Total } \\
108 \\
99 \\
9\end{array}$ & $\begin{array}{c}\text { P-value } \\
\nabla 0.41\end{array}$ \\
\hline $\begin{array}{l}\text { Parity } \\
\text { First parity } \\
\text { Second and above }\end{array}$ & $\begin{array}{l}23(28.1) \\
37(27.6)\end{array}$ & $\begin{array}{l}59(71.9) \\
97(72.4)\end{array}$ & $\begin{array}{c}82 \\
134\end{array}$ & $\nabla 0.95$ \\
\hline $\begin{array}{l}\text { Education level } \\
\text { Never gone to school } \\
\text { Primary education } \\
\text { Higher education }\end{array}$ & $\begin{array}{c}9(47.4) \\
39(30.5) \\
12(17.4)\end{array}$ & $\begin{array}{l}10(52.6) \\
89(69.5) \\
57(82.6)\end{array}$ & $\begin{array}{c}19 \\
128 \\
69\end{array}$ & $\Delta 0.02$ \\
\hline $\begin{array}{l}\text { Marital status } \\
\text { Married } \\
\text { Not married }\end{array}$ & $\begin{array}{l}26(20.2) \\
34(39.1)\end{array}$ & $\begin{array}{c}103(79.8) \\
53(60.9)\end{array}$ & $\begin{array}{c}129 \\
87\end{array}$ & $\square 0.002$ \\
\hline $\begin{array}{r}\text { Table-VII. Distributior } \\
\text { of the pregnant w } \\
\text { Key: } \boldsymbol{\nabla}=P>0.05 \\
\text { higher education } w \\
\text { health practice } t \\
=P<0.05 \text { (marri } \\
\text { adequate oral } \\
\text { ste }\end{array}$ & $\begin{array}{l}\text { of specific so } \\
\text { nen by their o } \\
\text { orogoro Tanza } \\
\text { significant); } \Delta= \\
\text { e significantly } n \\
\text { n those who ne } \\
\text { women were } s \\
\text { alth practice tha } \\
\text { stics: Chi-Squar }\end{array}$ & $\begin{array}{l}\text { iial demogr } \\
\text { ral health p } \\
\text { inia. } \\
=P<0.05 \text { (wo } \\
\text { nore with adec } \\
\text { ver went to sc } \\
\text { ignificantly m } \\
\text { n unmarried c } \\
\text { e test. }\end{array}$ & $\begin{array}{l}\text { men wit } \\
\text { quate orc } \\
\text { chool); } \\
\text { ore with } \\
\text { ones); }\end{array}$ & $\begin{array}{l}\text { factors } \\
\text { e in } \\
\text { ith } \\
\text { ral }\end{array}$ \\
\hline
\end{tabular}

analysed. Only the level of education remained as a significant predictor of oral health attitude $(P<0.05)$. Marital status and the level of education remained to be predictors of oral health practice $(\mathrm{P}<0.05)$

respectively.

A total of 26 pregnant women participated in three FGD's conducted in three randomly selected Health facilities. The first focus group had 9 participants aging between16-25. The second and third focus group had 8 and 7 participant whose age ranged from 26-35 and 36-45 respectively. A summary of the outcome on the 5 themes discussed are narrated below.

I) Opinions whether oral health is important to general health.

Majority of the participants agreed that oral health is important to their general health. Most of them associated oral health with brushing teeth. "Oral health is important because keeping good oral health prevent oral diseases".

li) Side effects of poor oral health to the unborn baby.

Almost all the participants did not know if their poor oral health could cause harm to the unborn baby. Most of them thought that they are the ones affected and not the unborn baby.

"I have never heard of any harm to the unborn baby relating to poor oral health".

iii) Dental treatment is harmful during pregnancy. Majority of the participants perceived that dental treatment is harmful during pregnancy. "It is dangerous yes, because when you go to some dental clinic a Doctor has to take $\mathrm{x}$-rays before treating your teeth. X-ray can cause blindness to the baby."

iv) Importance of dental visits for regular checkups.

Regular dental check-ups were not generally considered important among all three groups. "How can I go while I do not have a problem? It is costly you know and life is very tough nowadays."

v) Pregnancy causes susceptibility to oral diseases. 
Periodontal diseases and oral mucosal disorders were not always considered as oral diseases to them. "I think anybody is susceptible to bleeding gums but I wonder whenever I become pregnant my gums swell and they bleed but since I do not feel pain I take it as a normal experience".

\section{DISCUSSION}

Response information and background characteristics of the participants interviewed in this study were interesting in respect to their oral health knowledge, attitude and practice. Overall oral health knowledge was adequate. Similar findings were reported elsewhere in Tanzania and Saudi Arabia among the antenatal clinic population ${ }^{11,12}$. The current findings were contrary to those reported in Jordan ${ }^{13}$ where minority of the pregnant women were reported to have some knowledge on oral health. Adequate knowledge disclosed in the current study could probably be the result of an increased awareness on oral health as the result of oral health education programs that have been designed and directed at employees in sugar factories and villages in Morogoro district, Tanzania ${ }^{14}$.

Information received from educational health workers and media may also have been a contributing reason for the participants to exhibit adequate oral health knowledge. Majority of the respondents answered correctly on the question relating to frequency of sugary food consumption and dental caries. However, majority could not link bleeding of the gums with periodontal diseases. This gap was demonstrated more in FGD's where the women felt that bleeding gum during tooth brushing is normal since there is no pain. These findings were similarly reported elsewhere ${ }^{15}$. Education on effective tooth brushing to prevent periodontal diseases is needed in the current population.

Half of the participants interviewed in the current study knew that poor oral health has side effects to the unborn baby. Similar findings to these were reported elsewhere $^{16}$. On the contrary, FGDs' findings from the current study showed participants not to understand the relationship between poor oral health and its effects to the unborn baby. Many claimed that they have never heard of the association. The discrepancy outcomes on this particular question could have resulted due to response bias of the participants during the interview. Respondents could have tried to give the desirable answers without understanding the real concept of the question. All the specific demographic factors analyzed in this study were not associated with oral health knowledge. This was in contrast with the reports of similar study in Australia ${ }^{17}$ and Malaysia ${ }^{18}$ where education and age were significantly associated with oral health knowledge. Probably this could be due to the differences in the social backgrounds in these populations. In the current study majority of the pregnant women $(76 \%)$ had positive attitude towards oral health.

Majority of the participants in both quantitative and qualitative responses claimed equivocally that oral health is important for them and for their unborn babies. In a holistic health planning for this population this may predict compliance to dental visits as part of routine antenatal care. Majority of the participants agreed that oral health is important for general health. Majority of the respondents in this study felt that it is essential to brush their teeth every day. Similar study elsewhere ${ }^{17}$ reported the same findings. Almost all participants in FGD's claimed that reason for tooth brushing is to remove foul smell from the mouth. This signifies that brushing teeth in this community is considered a routine practice. However, efforts for further oral health programme in this community should aim at educating people that tooth brushing is mainly for plaque removal which is a major cause of chronic periodontal diseases in antenatal clinic populations. About $70 \%$ of the respondents in the current study claimed that dental treatment is harmful during the period of pregnancy. Similarly a study in 
Northern Greece ${ }^{19}$ reported majority of the participants to claim the same outlook. The FGD's claimed that dental treatment is harmful during pregnancy because it can cause miscarriage if a tooth is extracted and that $x$-rays can cause blindness to the unborn baby. This demonstrated that a number of myths coupled with misguided dental treatment plans during pregnancy exist in this community. These may cause fear to the antenatal clinic population who may have needs or demand for dental treatment during pregnancy. Oral health education planned for the current antenatal care population should impart the right knowledge on planned and guided dental treatment during pregnancy.

The overall oral health practices among the participants in the current study were found to be adequate by $72 \%$. More than half of the respondents claimed to brush at the recommended frequency of at least twice a day. These findings concurred with those reported elsewhere in Tanzanian antenatal population ${ }^{20}$. However, daily brushing of teeth claimed by the majority in the present study may be related to what is considered right rather than the actual practice. Any oral health programme in this community which can actually make this population to practice according to these results would be more desirable. Visiting a dentist was not a normal routine in the current population. The main barriers of not attending to the dentist in the present study were discussed in the FGD's. Majority perceived routine visit to a dentist to be costly and unnecessary. They could not understand the reason of going to a dentist without being sick. Oral health education to establish understanding of routine dental visits and encourage the women on having insurance to cover up the cost of dental treatment can bridge this gap.

The current study showed strong statistical association between practice of oral health and education status of the participants. Women with no education were likely to have inadequate oral health practices than women with education $(\mathrm{P}<0.05)$. These findings were similar to those reported in Malaysian antenatal clinic population ${ }^{18}$. Furthermore this study showed that those participants who were married were most likely to have adequate oral health practice compare to those who were not married $(P<0.05)$. Probably marriage in this community place couple in a better position to practice good oral health due to highly placed responsibility in taking care of the family.

\section{CONCLUSIONS}

This study revealed that majority of the participants in Morogoro Municipality had overall adequate knowledge, attitude and practice towards oral health. Unsatisfactory knowledge on possible connections between bleeding gums and pregnancy and negative attitude towards dental visits were present. The level of education was significantly associated with oral health attitude and practice while knowledge remained independent of the socio-demographic factors analyzed. We recommend that oral health education to antenatal clinic population in this community should emphasize on attending to the dentist in the first stages of pregnancy as part of antenatal clinic care.

\section{ACKNOWLEDGEMENT}

This study was supported by Kilimanjaro Christian Medical University College, Tanzania. The authors are grateful to the authorities of Morogoro Regional Administrative Office, Tanzania, for allowing this study to be undertaken and the health facilities visited for their cooperation.

\section{Copyright@ 25 Feb, 2013.}

\section{REFERENCES}

1. National Maternal and Child Oral Health Resource Center (NMCOHRC). Access to Oral Health Care during the Perinatal Period. A Policy Brief 2008, Accessed on May 17, 2009 at:http://www.mchoral health.org/materials/perinatal.html.

2. Laine M. Effect of pregnancy on periodontal and dental health. Acta Odontol Scand 2002; 60: 257-264. 
3. Offenbacher S, Katz V, Fertik G, Collins J, Boyd D, Maynor G, McKaig R, Beck J. Periodontal infection as a possible risk factor for preterm low birth weight. J Periodontol 1996; 67:1103-1113.

4. Ibrahim EM, Mary M. Oral health experience during pregnancy and dental service utilization in Bariadi Council, Tanzania. Tanzania Journal of Health Research; Doi: http://dx.doi.org/10.4314/thrb.v14i2.8.

5. Agbelusi G, Sofa 0, Jeboda S. Oral health knowledge, attitude and practices of pregnant women in the Lagos University Teaching Hospital. Nigerian Quarterly Journal of Hospital Medicine 1999; 9: 116 120.

6. Noorchpoung R, Dejpitak A, Yoshitoku Y, Harun R, Junich $S$. Dental caries and gingivitis among pregnant and non- pregnant women in Chiang Mai, Thailand. Nagoya J Med Sci 2010; 72: 43-50.

7. Akila G, Navin I, Preena C, Chandrasekhara R. A Survey on Dental knowledge and gingival health of pregnant women attending Government Maternity Hospital in Chennai. Journal of Oral Health Community Dentistry 2011; 5: 24-30.

8. Keirse MJ, Plutzer K. Women's attitudes to and perceptions of oral health and dental care during pregnancy. Journal of Perinatal Medicine 2010; 38: 38.

9. Smyth E, Caamano F, Fernández-Riveiro P. Oral health knowledge, attitudes and practice in 12-year-old schoolchildren. Med OralPathol Oral Cir Bucal 2007; 12: E614-620.

10. Al-Omir M, Al-Wahadni A, Saeed N. Oral health attitudes, knowledge, and behaviour among school children in North Jordan. J Dent Educ 2006; 70: 179 187.

11. Mwaiselo R, Masalu J. Oral health knowledge and behaviour among pregnant women in Kyela District, Mbeya, Tanzania. Tanz Dent J 2007; 14: 47-52.

12. Mansour K. A survey of dental knowledge in Al Jubail Antenatal Clinic Population. The Saudi Dental Journal

13. Alwaeli $\mathrm{H}, \mathrm{Al}$-Jundi S. Periodontal disease awareness among pregnant women and its relationship with socio-demographic variables. Int J Dent Hyg 2005; 3 : 74-82.

14. Lembariti FJ, Pilot T. Prevalence and severity of periodontal conditions among adults in urban and rural Morogoro, Tanzania. Community Dent Oral Epidemiol 1988; 16: 240-243.

15. Safia A A. The effect of Socio-demographic factors on the oral health knowledge, attitude and behaviour in a female population. Saudi Dental Journal 2007; 19: 2736.

16. Al Habashnesh R, Guthmiller JM, Levy S, Johnson GK, Squier C, Dawson DV, Fang Q. Factors related to utilization of dental services during pregnancy. Journal of Clinical Periodontology 2005;32: 815-21.

17. Natalie J, Philippe F, Middleton C, Crowther. Dental health care practices in pregnant women in Australia: a postnatal survey. BMC Pregnancy Childbirth; doi:10.1186/1471-2393-8-13.

18. Norkhafizah S, Azizah Y, Yew H. Factors associated with dental visit and barriers to utilization of oral health care services in a sample of antenatal mothers in Hospital Universiti Sains Malaysia. BMC Public Health; doi: 10.1186/1471-2458-10-75.

19. Dinas K, Achyropoulos V, Hatzipantelis E, Mavromatidis G, Zepiridis L, Theodoridis T, Dovas D, Tantanasis T, Goutzioulis F, Bontis J. Pregnancy and oralhealth: utilization of dental services during pregnancy in Northern Greece. Acta Obstetricia et Gynecologica Scandinavica 2007; 86: 938-944.

20. Mumghamba E, Manji K, Michael J. Oral hygiene practices, periodontal conditions, dentition status and self-reported bad mouth breathe among young mothers, Tanzania. International Journal of Dental Hygiene 2006; 4: 166-173. 
AUTHOR(S):

1. DR. BYANAKU A K

Department of Dentistry,

Morogoro Regional Hospital, Tanzania.

2. DR. RWAKATEMA D S

Department of Dentistry,

Kilimanjaro Christian Medical University College, Tanzania.

\section{Correspondence Address:}

Dr. Byanaku A K

Department of Dentistry, Morogoro Regional Hospital, P.0.Box 110, Morogoro, Tanzania. isherbyanaku@yahoo.com

Article received on: 17/09/2012 Accepted for Publication: 25/02/2013 Received after proof reading: 25/03/2013

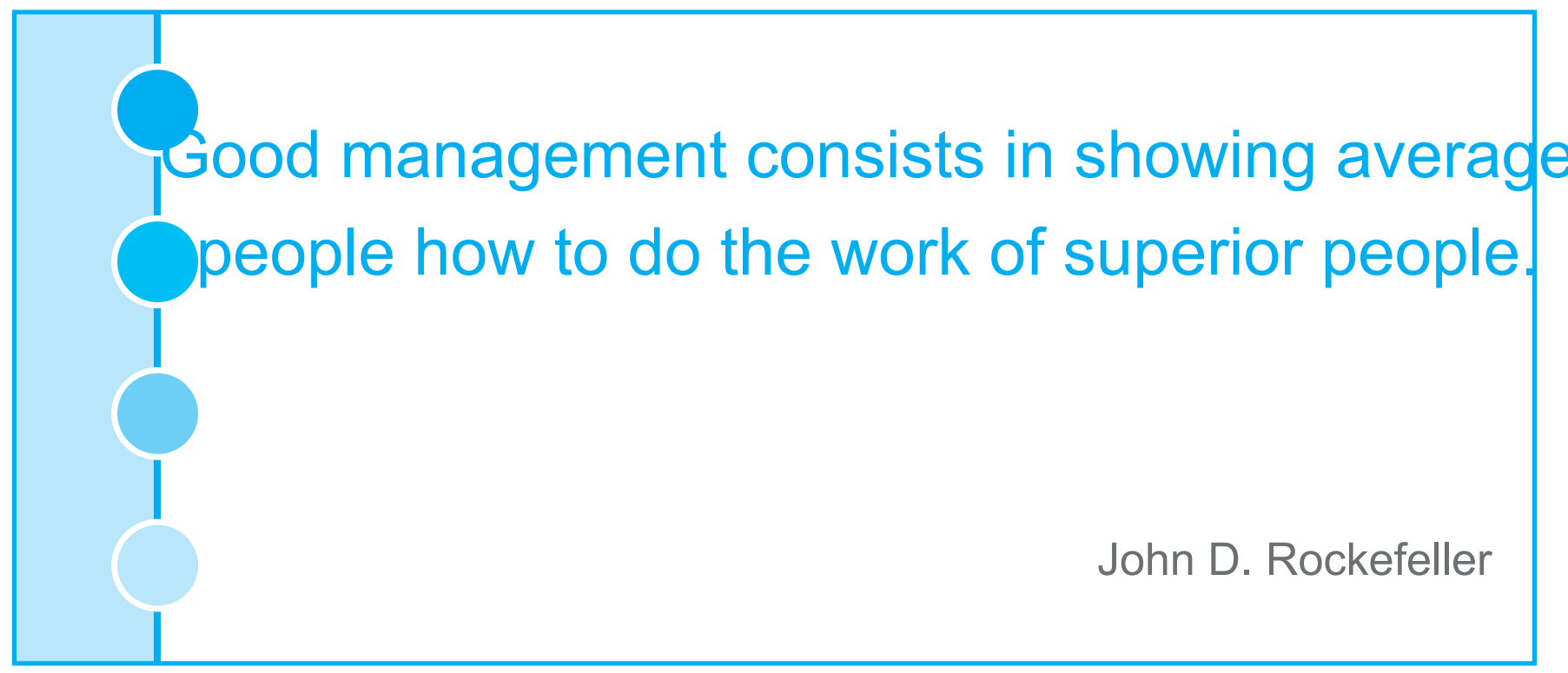

